Alcohol and Alcoholism

\title{
Treating alcohol problems: making ends meet
}

\author{
RICHARD SMITH
}

Tens of thousands of people in Britain and millions around the world must spend some of their time dealing with alcohol problems. Apart from those working in specialist units treating patients dependent on alcohol, there are physicians managing the physical problems produced by alcohol; trauma teams patching up those injured in accidents or violence associated with drinking; general practitioners wrestling with the whole gamut of problems; social workers helping with marriages, families, and careers wrecked by alcohol; voluntary counsellers and Alcoholics Anonymous workers organising aid; policemen dealing with violence, crime, and accidents; judges and lawyers allotting blame and compensating for alcohol-induced damage; Salvation Army members and others, including prison officers, working with vagrant alcoholics; and ordinary people trying to help friends and relatives having problems with alcohol. This list is far from complete, but it serves as a reminder that, although articles on treatment (including this one) usually concentrate on the treatment of those dependent on alcohol, many other kinds of "treatment" are needed for alcoholassociated problems.

Several profound questions have been raised in the last few years about the treatment of alcohol dependency. The most profound is one that cannot be answered with absolute confidence: whether treatment is any more effective than no treatment. Next, researchers have questioned the relative effectiveness of many kinds of treatment: for example, is prolonged, intensive, inpatient treatment necessarily better than short episodes of outpatient treatment? One particularly hot question has been over the aim of treatment: should it be abstinence, the traditional aim, or can those dependent on alcohol be taught to drink in moderation? Finally, apart from questions of aim and efficiency, those responsible for organising treatment services for people with alcohol problems worry about the logistics of the exercise: how can the limited resources ever be stretched to cope with a rising tide of problems.

\section{The "natural history" of alcohol problems}

A useful prelude to considering these questions is to look at what happens to alcoholics if they are "left to themselves"that is, studied in society rather than in relation to a clinic. Wide discrepancies exist, as explained in the first article (26 September, p 835), between the numbers who have alcohol problems and the number who come forward for treatment. Estimates of the number of problem drinkers in England and Wales range between 700000 and $1300000 .{ }^{1}$ Yet only about 20000 National Health Service patients are admitted for the treatment of alcohol dependence each year. Alcoholics Anonymous has about 10000

British Medical Journal, London WC1H 9JR

RICHARD SMITH, BSC, MB, assistant editor members, and Britain has about 30 local councils on alcoholism. ${ }^{1}$ Many problem drinkers must cope on their own, and those seen in clinics may be different from those in the community, which is one reason why insights into the "natural history" of problem drinkers are so interesting, but, not surprisingly, such studies are few and far between.

George E Vaillant of Harvard Medical School has reported the preliminary results of a longtitudinal study of 456 innerBoston 14-year-olds followed up for 35 years from $1940 .^{2}$ With data collected over such a long period, during which thinking on alcohol problems has changed dramatically, there must always be worries about the quality of the information and the relevance of the definitions used. Nevertheless, during those 35 years 110 developed four or more of the symptoms of alcohol abuse as defined by the American Psychiatric Association (a staggering proportion-almost a quarter). Of that 110,49 subsequently achieved at least one year of abstinence and 22 were able to return to social drinking. About a third of the 49 who became abstinent, and nine of the men who returned to social drinking, did so with the aid of professional treatment, and about a third who became abstinent had been helped by Alcoholics Anonymous. Most, however, had "helped themselves," and Vaillant was able to identify various factors that helped the men to return to abstinence.

Firstly, 53\% found help by substituting for alcohol food, cannabis, gambling, meditation, three packets of cigarettes a day, or compulsive hobbies. Secondly, $48 \%$ developed a medical problem that was instantly made worse by drinking and so reminded them constantly of the need to change their drinking habits. Thirdly, a third were helped by finding "a new love object" or "an unambivalent human relationship." Vaillant has suggested, as have others, that studying these "natural factors" that aid recovery may be a rich subject for research.

\section{Does treatment work?}

The more fundamental a question the less likely it is to be asked, but studies such as Vaillant's quoted above and others comparing complicated and intensive treatments with simple ones have led some people to question whether treating patients with alcohol problems is any more effective than leaving them to deal with their own problems. The question cannot be definitively answered, but some evidence is available.

The methodological problems of studying the effectiveness of treatment are formidable. Firstly, what is being treated: no clear definition of who is alcohol dependent exists (or can exist), and very different kinds of patients may be used in studies. Just as the starting point is hard to define so defining what constitutes improvement is difficult. Some studies define abstinence as the aim, whereas others measure success in terms of decreased alcohol consumption, "normal" behaviour, stability of marriage and family, and keeping a job. Furthermore, the length of follow-up is often widely variable, although some evidence exists that the remission rate after six months is a good predictor 
of remission rates at later dates. ${ }^{3}$ A particular problem when comparing treatment with no treatment is that, although they may have little evidence proving the effectiveness of their treatments, few treatment agencies understandably would consider turning away those who seek help for their alcohol problems. Thus, although there are many studies of the outcome of treating alcohol dependency, few are of the highest quality. Emrick ${ }^{4}$ has completed one of the largest reviews of reports on the outcome of treatment, yet some alcohol researchers think that he was forced to lump together such disparate studies that his overall data may mean little. Nevertheless, his work is widely quoted as not much else is available, and if the limitations are remembered it is useful to consider his results.

He reviewed data from seven studies of alcoholics who received no treatment and compared the results with 17 studies where the patients were given minimal treatment. Patients were followed up for at least six months, and of those who were not treated $13 \%$ were abstinent and $41 \%$ were improved; of those who received some minimal treatment $21 \%$ were abstinent and 43\% were improved. Emrick calls for caution in interpreting these results, but they do provide further evidence that some alcoholics can stop drinking without any professional help and they suggest that motivated alcoholics can without treatment change their drinking habits as much as those minimally treated. One study reviewed by Emrick was methodologically more sound than most of the others in that it was a randomised controlled trial. ${ }^{5}$ Sixty alcoholics randomly received either intensive, conventional inpatient treatment or inpatient treatment where all the formal aspects of the usual treatment were discontinued and the onus for seeking further help was placed on the patient. After one year there was no difference in outcome between the two groups. As Anthony Clare has said, "it remains to be established that minimal forms of treatment are any more effective in modifying alcoholic patterns of drinking than no treatment at all.",

\section{Intensity of treatment}

Comparing different kinds of treatment is just as difficult as comparing no-treatment with treatment, but much more has been done and slightly firmer conclusions can be reached. Emrick reviewed 384 studies of psychologically orientated treatment and identified only five that showed significant superiority of one treatment over another. ${ }^{4}$ On closer examination, however, most of these studies were methodologically flawed in some way, and his final conclusion was that different treatments did not significantly effect long-term outcome. Costello pooled results from 58 studies reporting a one-year follow-up and from 23 reporting a two-year follow-up. ${ }^{5 \mathrm{a}}$ The

Results of Costello's review ${ }^{5}$ of studies of outcome of treatment for alcohol dependence from 1952-72

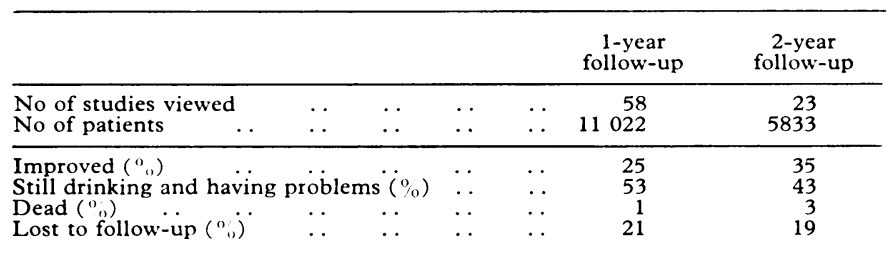

results (table) showed that a quarter to a third of problem drinkers were improved, and Costello attempted to identify factors associated with poor and good outcome. His analysis suggested that active, prolonged, intensive, and inpatient treatments were associated with a good outcome, whereas not selecting patients, large numbers in treatment, poorly motivated patients, and meagre resources were associated with a poor outcome. That poor motivation and lack of selection are associated with a poor outcome is not surprising, but the association between inpatient treatment and good outcome is likely to be an artefact. In the years that Costello studied (1957-72) inpatient treatment was the norm for selected, motivated patients.

Other evidence suggests that inpatient treatment is no better than outpatient treatment. Baekeland et $a l^{6}$ could find no evidence that one was better than another. They mention in their conclusions how: "Over and over we were impressed with the dominant role the patient as opposed to the kind of treatment used on him played both in his persistence in treatment and his eventual outcome." Edwards and Guthrie conducted a wellcontrolled trial of inpatient against outpatient treatment and found no significant difference in outcome after six and 12 months. ${ }^{2}$

In an important and influential study Edwards $e t$ al took this work further and compared intensive conventional treatment with simply "advice." 8 One hundred married men were studied and randomly allocated to "treatment" or "advice" groups: the two groups were well matched. The treatment group were offered an introduction to Alcoholics Anonymous, calcium cyanamide, and drugs to cover withdrawal; they were seen repeatedly by psychiatrists and social workers. Their wives were also counselled, and if response to outpatient care was poor then the men were offered inpatient care in a specialist unit. In other words, they were offered as good a care as Britain can offer. After three-hour assessments and initial counselling sessions with their wives those in the other group were given advice with their wives still present. They were told that they were alcoholics, that they should aim at complete abstinence, and that the responsibility was theirs. They were not seen again at the clinic. After 12 months there was no significant difference between the two groups in terms of drinking behaviour, subjective ratings, or social adjustment.

The authors warn against drawing nihilistic conclusions from their study, but certainly this study and other evidence suggests that when the number of people with alcohol problems is so large and the services are so limited it may be a wise policy to concentrate on simpler, cheaper forms of treatment.

\section{Behavioural approaches to alcohol problems}

Evidence is slowly accumulating, however, that one treatment -behaviour psychotherapy-may be consistently more effective than other treatments. ${ }^{9-11}$ Behaviour psychotherapists are less concerned with the mind of the alcoholic and more concerned with his behaviour and environment. They attempt to identify cues to drinking and the consequences of drinking and then modify the patient's drinking by strategies such as providing other ways of responding to the cues that would normally lead to drinking and "rewarding" abstinence and controlled drinking and "punishing" excessive drinking.

Some of the most impressive studies of behaviour psychotherapy for alcoholics have been carried out in California by Sobell and Sobell. ${ }^{910}$ They used some intriguing techniques: filming the patients when drunk and showing them the film later when they were sober; giving the patients tasks that were impossible and then discussing better ways of coping with failure; asking the patients to drink in a simulated bar and then giving them an electric shock when they gulped or drank too fast; and, finally, identifying the cues to drinking and trying to find other ways of dealing with them-for example, one patient threw out of his home his brother, who had been sponging off him and trying to seduce his wife, and thereafter he had few problems with alcohol.

Sobell and Sobell studied 70 alcoholic men who were randomly assigned to conventional treatment or behaviour psychotherapy. After one and two years those treated with behaviour psychotherapy had done significantly better in terms of many outcome measures, including drinking, emotional adjustment, and 
occupation. Such treatment, however, is expensive, intensive, and difficult, and it could not possibly be applied to all those in Britain with alcohol problems. Even when progress is being made with the techniques of treatment the logistic problems remain-indeed, are growing daily worse.

\section{Alcoholics Anonymous}

The only treatment agency not so hindered by logistic problems is Alcoholics Anonymous, the most successful self-help group ever. Controlled studies of its effectiveness are not possible, but most people interested in and treating alcohol problems believe that it is highly effective for some individuals. It started in Ohio in 1935, spread to Britain in 1948, and now has over a million members around the world. The achievement of Alcoholics Anonymous has been not only to help many individuals but also to contribute considerably to changing public attitudes towards those with alcohol problems: it played a large part in substituting "alcoholic" for "drunk." But this very success has led to some of the problems with Alcoholics Anonymous, which is unhappy with the erosion of the concept of alcoholism as a disease and the introduction of new ideas like controlled drinking as an aim of treatment.

David Robinson has studied the activities of Alcoholics Anonymous and described them in Talking Out of Alcoholism. ${ }^{12}$ Talking is at the core of Alcoholics Anonymous, and the alcoholic, who often has great difficult in recognising his problem and discussing it with others, by "telling his story" at the meetings and listening to the stories of others comes to cope with his problem. Although Alcoholics Anonymous concentrates on alcohol problems it provides much more: companions, help with other problems, and what in some cases amounts to a whole way of life. Members participate in all kinds of projects and activities and "cope through involvement."

Not everybody, however, reaches sobriety through Alcoholics Anonymous, and many alcoholics would never go near it. Yet clearly it has provided help for a huge number of people with alcohol problems, and without it Britain's problems with alcohol would be very much worse.

\section{Abstinence versus controlled drinking}

One particular issue that has generated much heat is whether controlled drinking rather than abstinence is an acceptable aim of treatment. ${ }^{13} \mathrm{~A}$ central tenet of both Jellinek's disease model of alcoholism and of Alcoholic Anonymous's programmes was that alcoholics were powerless against alcohol: the smallest drop of alcohol might be enough to return a dried-out alcoholic to the path of ruin. No hard evidence supported this idea: it was dogma. In 1962 Davies published a paper which showed that some alcoholics at least could return to social drinking without subsequently coming to disaster. ${ }^{14}$

The whole issue, which has simmered discretely in "socioscientific circles," was thrown into the public arena by the publication of the Rand report in $1976 . .^{15}$ This large study showed that alcoholics who had returned to social drinking after six months were no more likely to relapse after 18 months than those who were abstaining after six months. The methodology of the report was severely criticised, but on subsequent analysis the important points stand. ${ }^{16}$ Indeed, controlled drinking has come to be an accepted aim of treatment, and some studies have shown impressive results. ${ }^{910}$ Whether programmes that aim at controlled drinking are better than those that aim at abstinence is not clear, and probably there is a place and a need for both. ${ }^{17}$

This is an issue where the internecine argument ${ }^{18-20}$ whether the concept of the "alcohol dependence syndrome" is useful or not has particular importance. Hodgson ${ }^{20}$ has looked at the data of Armor ${ }^{1}$ and pointed out that "the degree of dependence" seems to be important in whether patients do better if the treatment aim is abstinence or controlled drinking.

\section{Conclusions on treatment}

So how should those responsible for devising policies for dealing with alcohol problems respond to these incomplete and confused reports on treatment? None of the researchers who have tried to compare the outcome of no-treatment and treatment have ever suggested that treating alcohol problems is a waste of time; and closing treatment units is neither politically possible or intellectually justified. But, as the Special Committee of the Royal College of Psychiatrists pointed out, ${ }^{21}$ we should recognise that in Britain in many ways we have only been pretending to mount a treatment response to alcohol problems: many of those with problems never encounter the treatment agencies; and the effectiveness of the agencies has rarely been properly evaluated.

The recommendations of the special committee seem eminently sensible. Skilled help should be available to all those who want and need it, but people should be encouraged to seek help earlier and to recognise that their own efforts in overcoming the problem are crucially important. Priority should be given to developing those treatments which have been proved to work and which can be applied to large numbers of people at low cost. Clearly such a policy will require considerable research to be done in developing new treatments and evaluating those we have.

\section{References}

${ }^{1}$ Office of Health Economics. Alcohol: reducing the harm. London: OHE, 1981.

2 Vaillant GE. The doctor's dilemma. In: Edwards G, Grant M, eds. Alcoholism treatment in transition. London: Croom Helm, 1980.

${ }^{3}$ Clare AW. How good is treatment? In: Edwards G, Grant M, eds. Alcoholism: new knowledge and new responses. London: Croom Helm, 1977.

4 Emrick CD. A review of psychologically oriented treatments of alcoholism. II. The relative effectiveness of different treatment approaches and the effectiveness of treatment versus no treatment. F Stud Alcohol 1975;36 : 88-108.

5 Levinson T, Sereny G. An experimental evaluation of "insight therapy" for the chronic alcoholic. Canad Psychiatr Ass f 1969;14:143-6.

5a Costello RM. Alcoholism treatment and evaluations : in search of methods. II. Collation of two year follow-up studies. Int $\mathcal{F}$ Addict $1975 ; 10: 857-67$.

${ }^{6}$ Baekeland F, Lundwall L, Kissin B. Methods for the treatment of chronic alcoholism: a critical appraisal. In: Gibbons RJ, Israel Y, Kalant $\mathbf{H}$, Popham RE, Schmidt W, Smart RG, eds. Research Advances in alcohol and drug problems. London: John Wiley and Sons, 1975.

${ }^{7}$ Edwards G, Guthrie S. A controlled trial of inpatient and outpatient treatment of alcohol dependency. Lancet $1967 ; \mathrm{i}: 555-9$.

${ }^{8}$ Edwards G, Orford J, Egert S, et al. Alcoholism: a controlled trial of "treatment" and "advice." F Stud Alcohol 1977;38:1004-31.

- Sobell MB, Sobell LC. Alcoholics treated by individualised behaviour therapy: one-year treatment outcome. Behav Res Ther 1973;11:599-618.

10 Sobell MB, Sobell LC. Second year treatment outcome of alcoholics treated by individualised behaviour therapy: results. Behav Res Ther 1976;14:195-215.

11 Hodgson R. Behaviour Therapy. In : Edwards G, Grant M, eds. Alcoholism: new knowledge and new responses. London: Croom Helm, 1977.

12 Robinson D. Talking out of alcoholism. London: Croom Helm, 1979.

${ }^{13}$ Heather BB. The crisis in the treatment of alcohol abuse. In: Madden JS, Walker R, Kenyon WH, eds. Aspects of alcohol and drug dependence. Tunbridge Wells: Pitman Medical, 1980.

${ }^{14}$ Davies DL. Normal drinking by recovered alcohol addicts. Quarterly Fournal of Studies on Alcohol 1962;23:94-104.

${ }^{15}$ Armor DJ, Polich JM, Stambul HB. Alcoholism and treatment. Santa Monica: The Rand Corporation, 1976.

15a Special Committee of the Royal College of Psychiatrists. Alcohol and alcoholism. London: Tavistock Publications, 1979.

16 Armor DJ. The Rand Reports and the analysis of relapse. In: Edwards G, Grant M, eds. Alcoholism treatment in transition. London: Croom Helm, 1980.

17 Miller WR, Caddy GR. Abstinence and controlled drinking in the treatment of problem drinkers. F Stud Alcohol 1977;38:986-1003.

18 Edwards G, Gross MM. Alcohol dependence: provisional description of a clinical syndrome. Br Med f 1976;i:1058-61.

19 Shaw S. A critique of the concept of the alcohol dependence syndrome. Br $\mathcal{F}$ Addict 1980;74:339-48.

${ }^{20}$ Hodgson RJ. The alcohol dependence syndrome: a step in the wrong direction. A discussion of Stan Shaw's critique. Br $\mathcal{F}$ Addict 1980;75: 255-63. 